\title{
Crop Prediction and Automation in Farmland
}

\author{
Hari Sankar Prabu $\mathrm{S}^{1}$, Ajith Kumar $\mathrm{P}^{1}$, KingslyJebaraj $\mathrm{S}^{1}$, Subhashini $\mathrm{A}^{2}$ \\ ${ }^{1}$ Student, Computer Science and Engineering, Dhanalakshmi College of Engineering, \\ Chennai - 601301. \\ ${ }^{2}$ Assistant Professor, Dhanalakshmi College of Engineering, Chennai-601 301.
}

\begin{abstract}
The development of technologies isn't meant only for urban areas, it also need to be deployed in rural areas, thus our project is an initiative to automate the activities that are done in farmland using IoT. This project includes various features like controlling farmland appliances sporadically, irrigating different crops depending upon its required conditions to grow, Temperature sensing, intruder's detection. It computes the climate present in the field and suggests which crop can be cultivated and what will be yield when it is cultivated, Different crops needs different soil $\mathrm{pH}$ for growth and depending upon the soil moisture the crop has to be watered optimally. It makes use of wireless sensor for noting various environment factors continuously and irrigates the crops through water pumps. This project focuses on reducing the human intervention and enhances the use of system intelligence in the field.
\end{abstract}

Keywords-IoT, AWSIOT, Dynamo DB, Sensors, Arduino UNO (AT MEGA 328), Live Streaming.

\section{INTRODUCTION}

The Internet of things (IoT) is an environment in which machine to machine communications and man to machine communication is made possible over a network without, where the user can access or operate irrespective of place.

Internet of things(IoT) is the network in which the tangible objects like sensors, peripherals devices like Arduino, USB, or any other machines can be connected and the data can be sent between them via a network. The IoT allows objects to accumulate and exchange data. Using IoT the devices are interconnected together the sensors can also be connected and the remote sensing can be done with high accuracy and efficiency as well as autonomously. Farmland is the land which is used for agricultural purpose, where the crops are cultivated and reaped. As the technology burgeons, the demand for technology is also burgeoning. The development of technologies isn't meant only for urban areas, it also need to be deployed in rustic areas, thus the project is an initiative to automate the activities that are done in Farmland using IoT. This Project includes various features like controlling farmland appliances sporadically and autonomously, as well as irrigating different crops depending upon its required condition to grow, temperature sensing, intruder's detection.

\section{A. Existing System}

Today most of the people follow the traditional cultivation system and the technology is merely used in the farmland. Though there are many systems which will perform smart irrigation in the field, there is not any system that will perform the irrigation depending upon the crop (as different crops require different soil moisture), as well as there is no predication of crop that will be suitable for particular land. The existing system only does either the smart irrigation irrespective of crops (or) the Motor ON/OFF that too not sporadically/autonomously. Thus to overcome these pitfalls and to have a full packaged system for Farmland following system is proposed.

\section{B. Literature Survey}

P.K Agerwal, Paresh B Shrisath and P.K Thornton proposed a system of climate-smart agriculture in different parts of the world to scrutinize the climatic factors of different regions, in which a spreadsheet is an output which states the crop yield of a specific area, based on region specific production [1]. The Arduino is used in the field to detect the temperature (sunlight in the atmosphere), humidity, soil moisture and is connected to Raspberry pi [2], [3], [4]. The connection of Arduino and raspberry pi is done so that the observed values of temperature, humidity and soil moisture can be transmitted to the cloud [5] IoT board sends the data to cloud, from where the moisture content, soil $\mathrm{pH}$, humidity can be viewed [6],[7]. The intruders can be detected, if someone enters the field, by surveillance system where the live feed is transmitted to cloud via raspberry pi [8]. Though the dripping system is present in the fields the smart dripping system enables dripping the water depending upon the necessity of the soil [9]. The environment monitoring system enables to scrutinize the Farmland, thus enabling farmer to view the optimum level of water content in the soil well as the existing water level in the soil [10]. 


\section{PROPOSED SYSTEM}

In a farmland different crops can be grown, but we don't know what is the exact crop that can be planted and what will give profitable yielding, thus depending upon the field's climatic values the optimum crop can be suggested. Though there are many smart irrigation systems available, the irrigation is done for the plant and not the specific plant (i.e.) different crops requires different water level and different soil moisture for its propitiousness, in our system the optimum irrigation is done. We can also control all the appliances like motors, lights in the field sporadically and autonomously using smart switch to overcome erratic power supply.

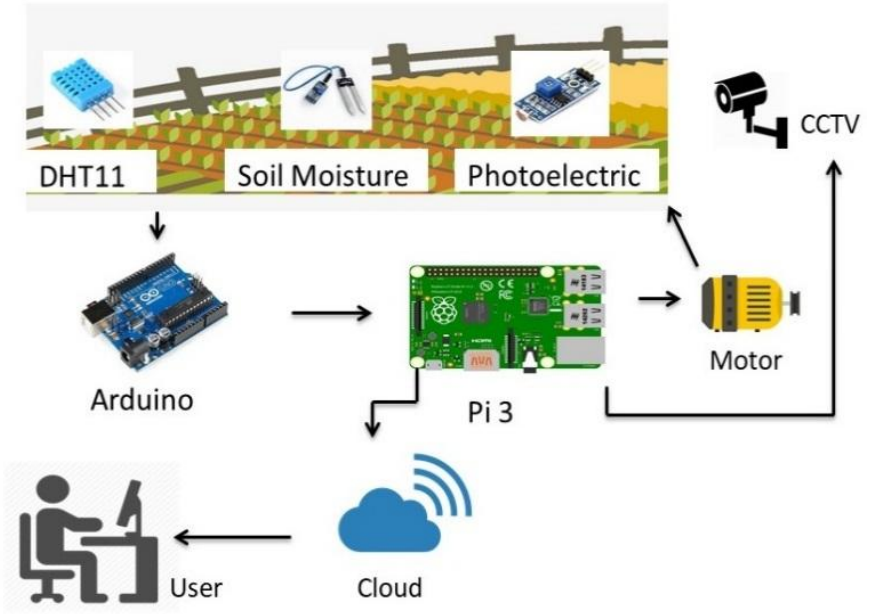

Fig. 1 Proposed System Architecture

\section{A. Materials and Methods}

1) Soil Moisture Sensor:Water is an essential element for the plant growth, if the optimum irrigation to the plants is not done, then it ultimately leads to death of the plant, the water is present in the soil.Soil moisture sensor is the one which is toevaluate soil water content. It measures the water content based on the dielectric constant. The dielectric constant in soil is directly proportional to the water content of the soil. The Dielectric constant present in the soil is always greater than the other components present in the soil. Thus, measurement of the dielectric constant gives a predictable estimation of water content.

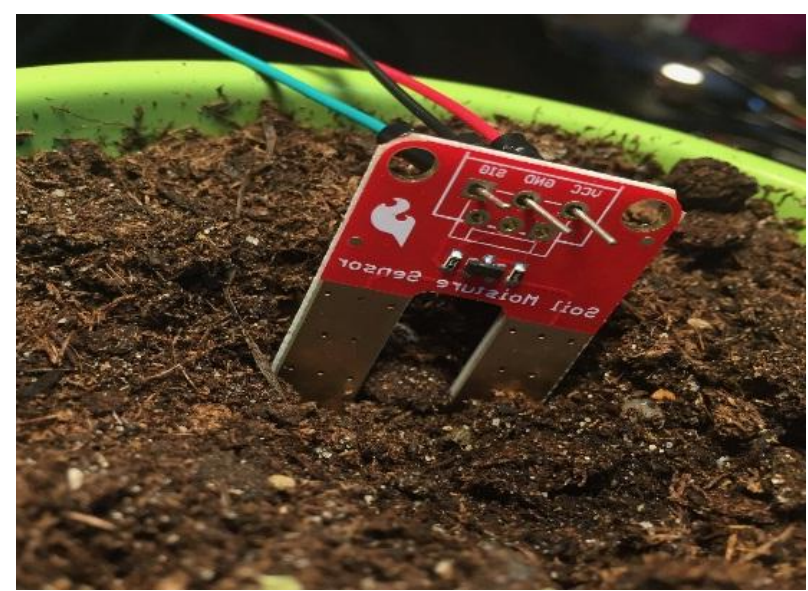

Fig. 2 Soil Moisture Sensor

2) DHT11 Sensor:The DHT11 sensor is used for temperature and humidity detection in the field. The DHT11 sensor has a 4pins, it works with 3 to $5 \mathrm{~V}$ power. Itmeasures temperature from $0-50{ }^{\circ} \mathrm{C}$ with an accuracy of $\pm 2{ }^{\circ} \mathrm{C}$ and relative humidity ranging from $20-80 \%$ with $\pm 5 \%$ accuracy. The communication between the sensor and a microcontroller is not possible through a direct interface,but with the peripheral devices it can be used to sense the values.

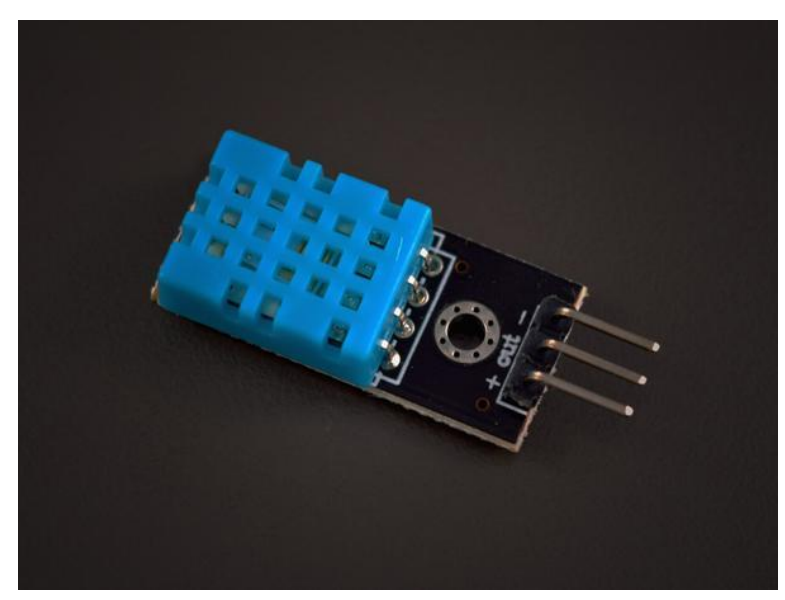

Fig. 3 DHT11

3) AWSIoT:The AWSIoT is the platform provided by Amazon, it is the cloud platform that lets connected devices to easily and securely interact with cloud applications and other connected devices. There is also AWS IoT button that will enable the users to program a button that will control the appliances based on Amazon dash button hardware. 


\section{amazon webservices $^{\text {tm }}$}

Fig. 4 AWS

4) Raspberry pi 3:The Raspberry pi is alike Minicomputer. It has 40 pins in it, in which there are 26 GPIO (General Purpose Input Output), and other pins are used for VCC and ground. Raspberry pi has inbuilt Wi-Fi receiver, Bluetooth and USB ports. The raspberry pi can be booted with many OS like Raspbian, Windows IoT core. Using GPIO the external appliances can be connected and controlled.

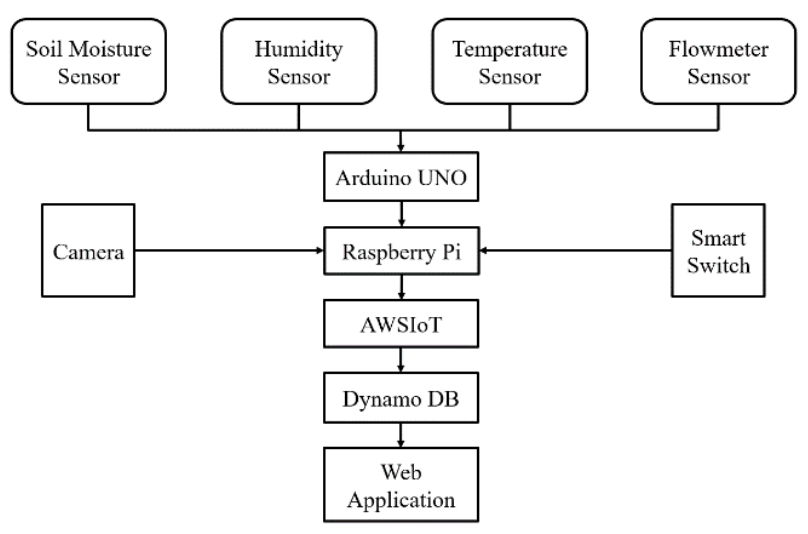

Fig. 5 Block Diagram

\section{SysteM DesIGN}

System has 3 units Input unit (Sensors), processing unit (Raspberry pi and Arduino) and output unit (User's machine).

\section{A. Input Unit}

The sensors act as the input unit, which will sense the climatic values present in the field. It senses the soil moisture, humidity and temperature using DHT11 and the amount of light present in the field.

\section{B. Processing Unit}

The processing unit is the raspberry pi and Arduino. The Arduino gets the values from the sensor and sends it to the raspberry pi, where the obtained climatic values are computed to get the optimum crop for the field, and is sent to the cloud and viewed in output unit.

\section{Output Unit}

Basically, the outputunit is the user system where the optimum crop and every other control of the appliances can be done.

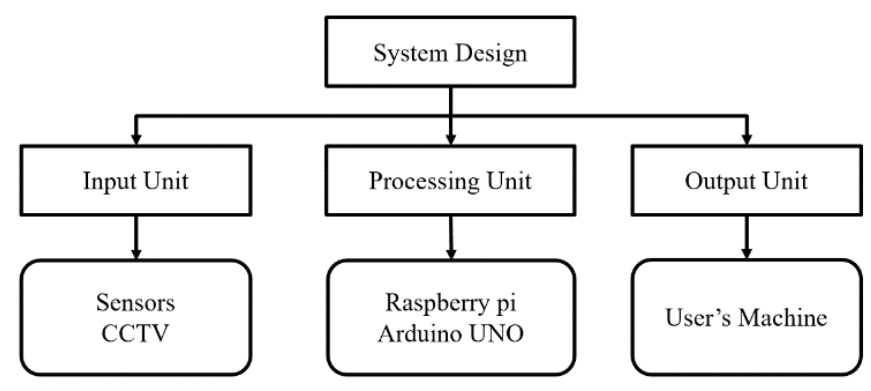

Fig. 6 System Design

\section{EXPERIMENT AND RESULTS}

Thus, the sensors detect the climatic values in the field and using predication algorithm the crop which will be suitable is predicted. Using Frontier timer, the required pattern is set so that the appliances ON/OFF sporadically as well as using Relay we can control the appliances from anywhere. The project results optimum irrigation depending upon the crop and also enables the user to control appliances as well as monitor the field for intruders.

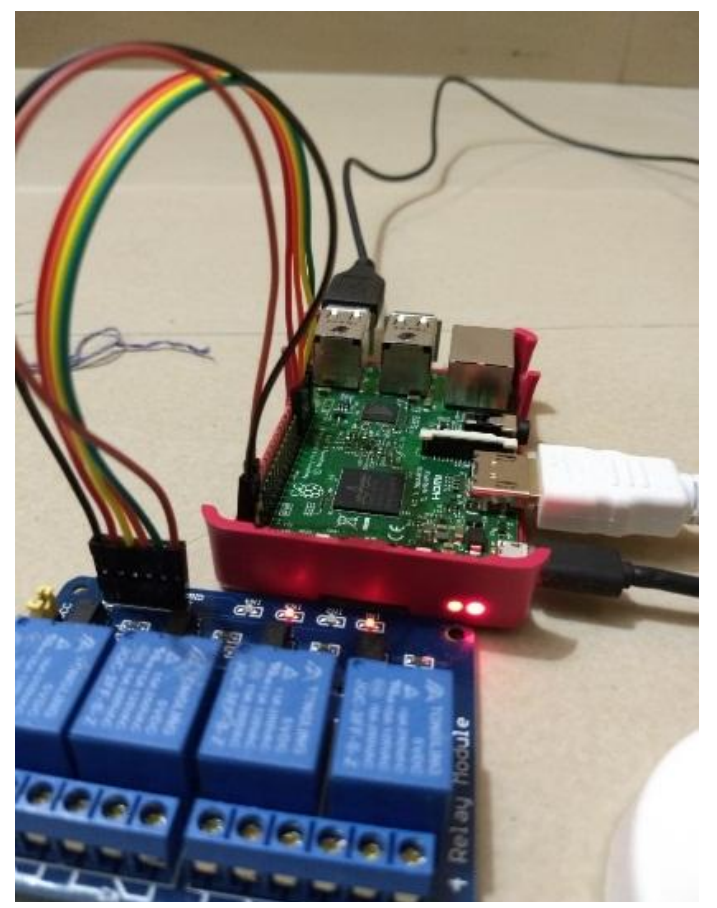


Fig. 7 Relay connected with Raspberry pi

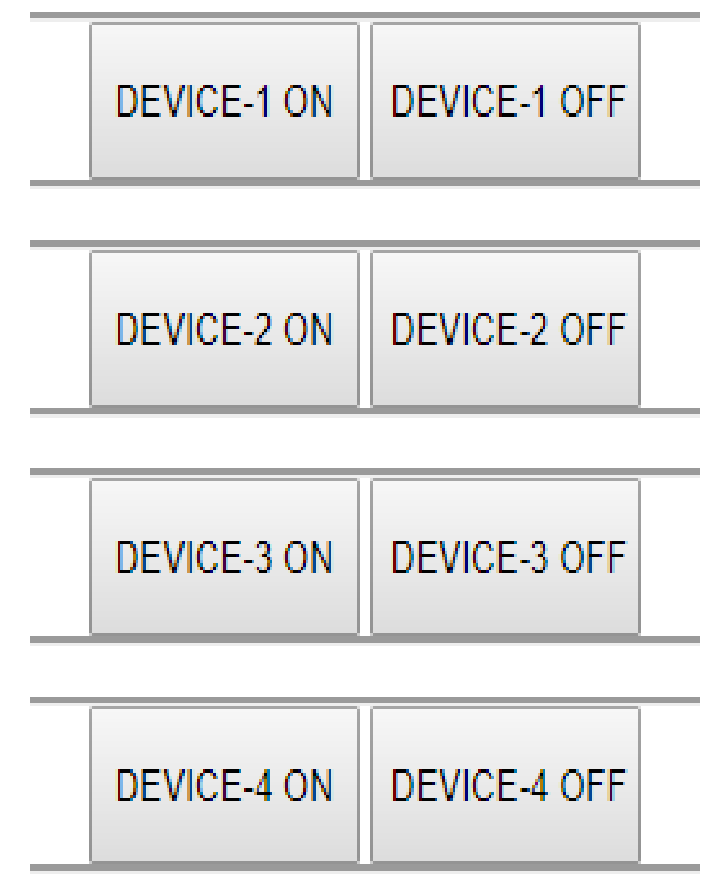

Fig. 8 Website to Control the Appliances

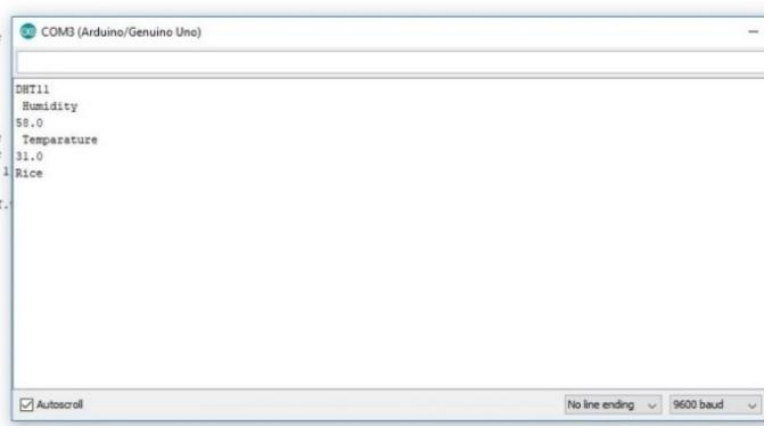

Fig. 9 Crop Predicted

\section{CONCLUSION}

The primary application of the proposed system is to find the apt crop depending upon the fields climatic conditions, and also to control the appliances sporadically as well as autonomously to avoid the erratic supply of water to field due to power shortage. The smart irrigation system irrigates the crops optimally. Using CCTV, the field can be monitored and the intrusion can be avoided. All the Controls of the appliances, Live feed of camera and output values of sensors can be viewed at user's machine via Cloud.

\section{REFERENCES}

[1] Paresh B Shirsath, P. KThornton, P.K. Agarwa, "Prioritizing climate- smartagriculture land use option at region scale" (Elsevier 2016).

[2] Arun kumbit, Pavankumar naik, Pavithra HK, Sushma BS - “Arduino based Smart irrigation system” (IJSCSEIT 2017 ).

[3] Apurva nagarae, Apurva nagarae, Mayur Bramhare, Sanjay kumawat. - "Sensor based irrigation system and detecting the $\mathrm{pH}$ of soil using image processing" (IRJET 2017).

[4] M.karthikeyan, V.Sasikala, R.Vagulbranan."Automatic irrigation system on sensing soil moisture content"(IRJET 2016).

[5] R.S. Kawitkar, Nikesh Goundachawar- "IoT based smart agriculture" (IJARCCE 2016).

[6] Deepika G,Divya M, Dhanalakshmi R,Hemalatha.D "Internet of Things (IOT) based smart irrigation" (IJARBEST 2016).

[7] Mehta Bavin, Shah Vatsal - "Using Raspberry pi to sense Temperature and humidity” (IRJET 2017).

[8] Padma MC, Srilakshmi C.M - "IoT based Smart surveillance system "(IRJET 2017).

[9] Khondoba, R.Jothi, S.Gunjatte - "Smart drip irrigation using raspberry pi and Arduino" (IJIRCCE 2017).

[10] Gaurav Jadhav, Kavitha Nadlamani, Kunal Jadhav "Environment Monitoring system using Raspberry pi" (IRJET 2016). 